\title{
Effect of Social Rank on Well-Being and Space Utilization of Dry Sows Kept in a Free Access Stall-Pen Housing Environment
}

\author{
Ashley E. DeDecker ${ }^{1}$, Janeen L. Salak-Johnson ${ }^{2 *}$ \\ ${ }^{1}$ Smithfield Foods, Inc., Warsaw, NC, USA \\ ${ }^{2}$ Department of Animal and Food Sciences, Oklahoma State University, Stillwater, OK, USA \\ Email: *janeen.johnson@okstate.edu
}

How to cite this paper: DeDecker, A.E. and Salak-Johnson, J.L. (2020) Effect of Social Rank on Well-Being and Space Utilization of Dry Sows Kept in a Free Access Stall-Pen Housing Environment. Open Journal of Animal Sciences, 10, 287-300.

https://doi.org/10.4236/ojas.2020.102017

Received: March 5, 2020

Accepted: April 20, 2020

Published: April 23, 2020

Copyright $\odot 2020$ by author(s) and Scientific Research Publishing Inc. This work is licensed under the Creative Commons Attribution International License (CC BY 4.0).

http://creativecommons.org/licenses/by/4.0/

\begin{abstract}
The primary objective of this pilot study was to evaluate the impact of social rank on the well-being of gestating sows housed in a free access stall-pen housing environment. At d 30 post-breeding, 32 multiparous crossbred sows in groups of 4 were allocated to a stall-pen housing environment. Blood samples were taken at gestational d 30 (before mixing) and d 31 (24-h post-mixing), and then again at $\mathrm{d} 89$ and 110; whereas, sow behavior was recorded at gestational d 30, 66, 87, and 102. Social rank was determined based on aggressive encounters, dyadic fighting wins and losses, and displacements between sows by 48 -h post-mixing. At d 31 (post-mixing), regardless of social rank, total WBC decreased and, lymphocyte counts increased, but $\%$ change was more significant among the subordinates than dominants. The same trend occurred with neutrophil chemotaxis increased more in subordinates, but ConA-induced lymphocyte proliferation increased more in dominants, whereas LPS-induced lymphocyte proliferation was reduced among dominants. Sow behavior was differentially affected by social rank and time-periods or gestational day, with subordinates spending more time sitting and drinking, especially during time-periods 1, 3, and 4. Dominants displayed more oral-nasal-facial behaviors during mid-gestation but more sham-chew during time-period 2, which included feeding time. Social rank also influenced the percentage of time sows spent in either the stall or pen area, with subordinates in stalls and dominants in pen. These data imply that social rank differentially influences physiology and behavior of dry sows housed in a free access stall-pen environment. More specifically, the location of the dominant sow, time of day, and activity may influence when and where the subordinates spend their time within this housing system.
\end{abstract}




\section{Keywords}

Behavior, Housing System, Endocrine, Immune, Pregnant Sows, Social Rank

\section{Introduction}

Worldwide there are a variety of group-housing systems being used for keeping gestating sows. The differences are primarily related to the type of feeding system, group-size, and group management. Nevertheless, inter-sow aggression remains a significant welfare concern in a group housing system, especially at mixing and/or around feeding. The welfare level of individual sows within a grouphousing system can vary greatly depending on the social rank of the animal. Often, low-ranking sows are the most vulnerable to social stress and may have poorer welfare when housed in group pens during gestation [1]. Often, they sustain more skin lesions as a result of inter-sow aggression than high-ranking sows [2]. Others have found that low-ranking sows have fewer opportunities to rest in preferred areas of a pen due to being threatened by higher-ranking sows [3]. Therefore, it is essential to transition toward more welfare-friendly group systems that improve sow well-being, especially the more vulnerable ones within the group.

The free-access stall-pen system (FAS) is one of the alternative housing environments that is viewed as a more welfare-friendly system since it incorporates individual walk-in, lock-in feeding stalls, and a group pen-area. Hence, this housing system provides the individual sow the opportunity to choose between being in a group-pen or an individual stall. Within the group-pen area, sows have the opportunity to interact with one another physically and behaviorally. However, there still is the opportunity to engage in aggression, which can potentially compromise the well-being of lower-ranking sows (subordinates). For example, Wang and $\mathrm{Li}$ [4] found that low-ranking sows were more likely to use the feeding stalls as hiding spaces to escape from the aggressive interactions during mixing, which reduced lesions caused by aggression but had no effect on performance. Animals of various social ranks cope differently both physiologically and behaviorally. Therefore, understanding the differential coping mechanisms that dominant and subordinate sows utilize when adapting to social and environmental stressors in a free-access stall system is vital to optimizing the physical housing components so that welfare is not compromised. There is limited scientific data on the effects of social rank on immunological and behavioral responses within this housing environment and space utilization. Therefore, the objectives of this pilot study were to evaluate how social rank impacts sow well-being and use of stall or pen space when dry sows are kept in a free access stall-pen housing environment.

\section{Material and Methods}

\subsection{Animals and Housing}

The study was conducted at the University of Illinois Imported Swine Research 
Laboratory (Champaign, IL, USA), and all protocols were approved by the Institutional Animal Care and Use Committee. A total of 32 Yorkshire x Landrace crossbreds sows were allotted to the free access stall-pen (FAS) housing environment at gestational d 30. The housing environment consisted of 4 walk-in/lock-in stalls and a pen area. The stall dimensions were $69 \times 226 \mathrm{~cm}$, and the small pen area outside of the stalls was $2.44 \times 1.46 \mathrm{~m}$ (LAAKE: CRB International Corp., Herzlake, Germany). This system allows the sow to choose when and if to utilize a group-pen area or remain in an individual self-locking stall. The pen area consisted of $173 \mathrm{~cm}$ of slatted flooring, which was continuous from the end of the back gate of the stall, and $81 \mathrm{~cm}$ of solid flooring beyond the slatted portion. The group size was held constant at four sows per replicate due to the number of stalls available within the FAS and the ability to determine social rank confidently.

Sows were manually fed daily at $6: 00$ am by the same animal caretaker in the same stall order. Feed was only added to the first stall once all sows entered their stall space, and the back gates were closed. Diet was formulated to meet or exceed established nutrient allowances [5]. Each sow was fed $2.3 \pm 0.45 \mathrm{~kg} / \mathrm{d}$ corn-soybased diet having a calculated composition (as fed basis) $12.5 \% \mathrm{CP}$ and providing a $\mathrm{ME}$ density of a calculated $3300 \mathrm{kcal} / \mathrm{kg}$. Sows were fed via trough, and each stall space was equipped with one nipple water drinker.

All sows were artificially inseminated within $24 \mathrm{~h}$ after estrus onset and again $24 \mathrm{~h}$ later. Pregnancy was diagnosed using a Pharvision B-mode ultrasound machine (AV 2100V; Ambisea Technology Corp., Hong Kong, China) for transabdominal examination. All sows were kept in conventional stalls until confirmed pregnant at d $29 \pm 2$ after breeding and then moved to the FAS housing environment where they remained until gestational $\mathrm{d} 110$ when they were moved to the farrowing facility.

\subsection{Social Rank}

Social rank was determined by live observations and video recorded behaviors during the first $48 \mathrm{~h}$ of being allotted to the free-access stall system in each block. If social rank could not be determined within the first $48 \mathrm{~h}$, proceeding days of gestation would be observed until confirmed. Behaviors used to determine social rank were agonistic encounters, aggression, and displacements. Each bout of dyadic fighting determined a winner and loser, therefore allowing determination of social rank amongst those animals. The initiator of aggression and aggression alone would result in the displacement of a con-specific, therefore also allowing determination of social rank. Social rank was only determined once each animal was engaged in one of the previously stated behaviors at least twice, with each con-specific kept in the free-access stall system. Previous studies reported that the percentage of agonistic encounters won was highly correlated with displacement success over "valuable" resources [6] [7]. We, therefore, concluded that assessing agonistic encounters, displacement, and additionally, aggression in the present study was more than suitable for determining social rank in all animals, especially with a group size of four. 


\subsection{Cell Counting and Isolation}

Sows were nose-snared (procedure lasted $\leq 2 \mathrm{~min}$ ). Blood samples were collected from sows at $\mathrm{d} 0$ (wean), 30, 89, 110 of gestation by vena-puncture of the jugular vein using vacutainers containing either sodium heparin or EDTA. Total white blood cell counts (WBC) were made electronically using a Coulter Z1 Particle Counter (Beckman Coulter, Miami, FL). Leukocyte differentials were made and manually counted using a light microscope to determine percentages of leukocyte cell populations. Whole blood was diluted with Roswell Park Memorial Institute (RPMI) medium (Gibco, Carlsbad, CA), layered over Hisptopaque-1077 (density: $1.077 \mathrm{~g} / \mathrm{ml}$; Sigma) and -1119 (density: $1.119 \mathrm{~g} / \mathrm{ml}$; Sigma), and centrifuged at $700 \times \mathrm{g}$ for $30 \mathrm{~min}$ at $25^{\circ} \mathrm{C}$. Lymphocytes were collected from the Hisptopaque-1077 layer, washed twice in RPMI, resuspended, and counted. Neutrophils and red blood cells were removed from the Hisptopaque-1119 layer and washed once in RPMI. Red blood cells were lysed using cold endotoxin-free water, and isotonicity was restored using $10 \times$ PBS. Neutrophils were centrifuged for $10 \mathrm{~min}$ at $475 \times \mathrm{g}$, supernatant was decanted, and the pellet was washed twice and resuspended in RPMI. Cell concentrations were adjusted with RPMI based on immune-assay requirements.

\subsection{Immune Assays}

Natural killer cell (NK) cytotoxicity was measured using a commercially available non-radioactive cytotoxicity-detection kit (Roche Diagnostics, Indianapolis, IN) as previously described [8]. Briefly, porcine lymphocytes were used as effector cells; K-562 chronic human myelogenous leukemia cells (American Tissue Type Culture Collection, Manassas, VA) as target cells. Lymphocytes were adjusted to $1 \times 10^{7}$ cells $/ \mathrm{ml}$ and $\mathrm{K} 562$ cells to a constant 10,000 cells per well. Samples were analyzed in triplicate at effector (lymphocytes): target-cell (K-562) ratios of 12.5:1, 25:1, 50:1, and 100:1, respectively. Results were measured using a microplate reader (BIO-TEK Instruments) at wavelength $490 \mathrm{~nm}$ and reference wavelength $690 \mathrm{~nm}$. The assay was considered valid if maximum release divided by spontaneous release was $\leq 20 \%$.

Neutrophil chemotaxis was measured using an assay previously described [9]. Briefly, neutrophils were used at a concentration of $3 \times 10^{6}$ cells $/ \mathrm{ml}$ to evaluate the ability of cells to migrate toward assay medium (control; random migration) or recombinant human complement-5a (hC5a; $10^{-7}$-M; Sigma) (chemotaxis; directed migration). Neutrophil phagocytosis was measured using a flow-cytometrybased assay as previously described [10] with minor modifications [11]. Fluorescent beads were pre-incubated $30 \mathrm{~min}$ with non-heat-inactivated porcine serum before beads were added to samples at a 10:1 (beads-to-neutrophils) ratio. Cells and beads were incubated together for $45 \mathrm{~min}$, and then the percentage of engulfment of fluorescent beads by cells was evaluated utilizing a flow cytometer.

\subsection{Cortisol}

Using a validated commercial radioimmunoassay (Coat-A-Count, Los Angeles, 
CA), plasma cortisol was measured following a protocol modified by Sutherland et al. [8]. Intra- and inter-assay CV were $4.5 \%$ and $8.5 \%$, respectively.

\subsection{Behavior}

Continuous sampling of individual sow behavior over a 24-h period was observed and registered in real-time on d 29, 30, 66, 87, and 102 of gestation. Both frequencies and durations were registered for drink, eat, lay, stand, sit, oral-nasalfacial (ONF), and sham-chew behaviors (Table 1). Data were divided into six 4-h periods across $24 \mathrm{~h}$ : period 1 (0301 to $0700 \mathrm{~h}$ ), 2 (0701 to $1100 \mathrm{~h}$ ), 3 (1101 to $1500 \mathrm{~h}$ ), 4 (1501 to $1900 \mathrm{~h}$ ), 5 (1901 to $2300 \mathrm{~h}$ ), and 6 (2301 to $0300 \mathrm{~h}$ ). Space utilization of group-pen and stall were also assessed by determining the percentage of observed time in each location.

\subsection{Statistical Analysis}

Data were analyzed with the mixed model procedure of SAS 9.3 [12]. All traits were tested for departures from a normal distribution, and natural logarithmic transformation was applied to all traits deviating from a normal distribution to facilitate the interpretation of results. A linear mixed-effects model was used to analyze the physiological measurements. The model included the fixed effects of social rank (2 levels: dominant and subordinate), day of measurement (level varies depending on measurement), and interactions among those and the covariate of the corresponding blood measurement at the start of the trial (d 0). A random effect of block was included in the model to account for potential environmental and management differences across groups. All measurements were from a single sow; thus, the experimental unit was the sow based on results from Hanson et al. [13]. A similar model to blood measurements was used for behavior and performance measurements, with hour being included in the behavioral model. Lesion scores being an ordinal variable required analysis with PROC GLIMMIX [12] to determine the means with a response distribution of Gaussian. Least square means were generated and separated statistically with pairwise $t$-tests (PDIFF option). Significance was set at $P \leq 0.05$, whereas trends were discussed at $P \leq 0.10$.

\section{Results}

\subsection{Interactive Effects of Social Rank by Day on Immune Response and Behavior}

An interactive effect of social rank by gestational day occurred for a few immune traits, with most differences being detected at 24-h post-mixing (d 31) when compared to baseline measure at d 30 post-breeding within social rank (Table 2). Total WBC counts decreased (22\% vs. $15 \% ; P<0.05)$, and lymphocyte counts increased ( $26 \%$ vs. $16 \% ; P=0.09)$, regardless of social rank, but $\%$ change was greater among the subordinate sows than dominants. The same trend occurred for other immune measures, with neutrophil chemotaxis increasing more $(214 \%$ vs. $38 \%, P<0.001)$ among the subordinates, but ConA-induced lymphocyte proliferation increasing more (96\% vs. $64 \%, P=0.05)$ among dominants (Table 2 ). 
Moreover, LPS-induced lymphocyte proliferation decreased among dominants $(P<0.05$; Table 2).

An interactive effect of social rank by gestational day also occurred for postural and oral behaviors among sows housed in the FAS environment. At gestational d 30 (2.15 vs. $0.36 \mathrm{~min})$ and d 66 ( 2.47 vs. $0.73 \mathrm{~min})$, subordinates spent more time sitting $(P<0.001)$ than did dominant sows; whereas, dominants spent more time $(P<0.05)$ performing ONF behavior at $\mathrm{d} 66(15.3$ vs. 5.9 no. $)$ than did subordinate sows. Drink bouts were also more $(P<0.05)$ frequent at gestational $\mathrm{d} 66$ (5.3 vs. 1.2 no) and $\mathrm{d} 102$ (4.4 vs. 1.1) among subordinates than dominant sows.

Table 1. Definitions of registered behaviors for sows housed in free access stall-pen housing environment.

\begin{tabular}{ll}
\hline Behavior & Description \\
\hline Lay & Sow reclining in ventral or lateral position \\
Sit & Sow supported by two front legs \\
Stand & Sow supported by all four legs \\
Eat & Sow's snout/mouth in contact with feed \\
Drink & Sow's snout/mouth in contact with nipple waterer \\
Oral-nasal-facial & Sow's snout or mouth in contact with any object besides food or water \\
Sham-chew & Sow's mouth empty while moving jaw in a repetitive chewing motion \\
\hline
\end{tabular}

Table 2. Effects of social rank on various immune traits pre-mixing (baseline, d 30) and 24-hours post-mixing (d 31) for gestating sows housed in a free access stall-pen housing environment.

\begin{tabular}{|c|c|c|c|c|c|}
\hline \multirow{2}{*}{ Immune traits } & \multicolumn{2}{|c|}{ Dominant } & \multicolumn{2}{|c|}{ Subordinate } & \multirow[b]{2}{*}{$P$-value } \\
\hline & $\begin{array}{l}\text { Baseline } \\
\text { (d30) }\end{array}$ & $24-\mathrm{h}(\mathrm{d} 31)$ & $\begin{array}{l}\text { Baseline } \\
\text { (d30) }\end{array}$ & $24-\mathrm{h}(\mathrm{d} 31)$ & \\
\hline Total WBC, $10^{7} / 10 \mathrm{~mL}$ & $2.6 \pm 0.10$ & $2.1 \pm 0.11$ & $2.7 \pm 0.11^{\mathrm{a}}$ & $2.0 \pm 0.12^{b}$ & 0.05 \\
\hline Neutrophils, $10^{7} / \mathrm{mL}$ & $5.7 \pm 0.63$ & $5.9 \pm 0.63$ & $5.7 \pm 0.61$ & $6.4 \pm 0.61$ & 0.77 \\
\hline Lymphocytes, $10^{7} / \mathrm{mL}$ & $2.7 \pm 0.28$ & $3.1 \pm 0.28$ & $2.6 \pm 0.28^{\mathrm{a}}$ & $3.3 \pm 0.28^{b}$ & 0.09 \\
\hline Neutrophils, \% & $31.6 \pm 3.1^{\mathrm{a}}$ & $40.0 \pm 3.1^{\mathrm{b}}$ & $32.6 \pm 3.0^{\mathrm{a}}$ & $40.5 \pm 3.0^{\mathrm{b}}$ & 0.07 \\
\hline Lymphocytes, \% & $60.4 \pm 2.3$ & $52.8 \pm 2.3$ & $58.8 \pm 2.2$ & $51.8 \pm 3.2$ & 0.10 \\
\hline Monocytes, \% & $3.8 \pm 0.4$ & $2.4 \pm 0.4$ & $3.7 \pm 0.6$ & $3.5 \pm 0.6$ & 0.78 \\
\hline Eosinophils, \% & $4.3 \pm 0.5$ & $4.9 \pm 0.5$ & $5.0 \pm 0.3$ & $4.8 \pm 0.3$ & 0.57 \\
\hline $\begin{array}{l}\text { Neutrophil-to-lymphocyte } \\
\text { ratio }\end{array}$ & $0.55 \pm 0.26$ & $1.03 \pm 0.26$ & $0.58 \pm 0.26$ & $0.92 \pm 0.26$ & 0.72 \\
\hline LPS-induced proliferation & $1.3 \pm 0.20^{\mathrm{a}}$ & $0.92 \pm 0.18^{\mathrm{b}}$ & $1.7 \pm 0.19$ & $1.3 \pm 0.20$ & 0.05 \\
\hline ConA-induced proliferation & $1.3 \pm 0.4^{\mathrm{a}}$ & $2.5 \pm 0.4^{\mathrm{b}}$ & $1.6 \pm 0.4$ & $2.6 \pm 0.4$ & 0.06 \\
\hline NK cytotoxicity, \% & $60.9 \pm 15$ & $56.9 \pm 15$ & $49.8 \pm 15$ & $62.8 \pm 15$ & 0.74 \\
\hline Chemotaxis, IL-8 & $39.4 \pm 16$ & $54.2 \pm 15$ & $29.5 \pm 18^{\mathrm{a}}$ & $92.6 \pm 15^{b}$ & $<0.001$ \\
\hline Chemotaxis, C5a & $34.1 \pm 8.1$ & $68.8 \pm 6.1$ & $38.2 \pm 8.1$ & $60.4 \pm 6.1$ & 0.37 \\
\hline Plasma cortisol, ng/mL & $28.9 \pm 2.2$ & $29.0 \pm 2.2$ & $30.9 \pm 2.3$ & $29.0 \pm 2.3$ & 0.85 \\
\hline
\end{tabular}

${ }^{\mathrm{a}, \mathrm{b}}$ Means with a different superscript within a row and social rank differed at $(P \leq 0.05)$ compared to baseline measure (gestational d $30=$ prior to mixing). 


\subsection{Interactive Effects of Social Rank by Time-Period on Behavior}

Sow behavior was differentially affected by social rank across different time-periods throughout gestation. During time-periods 1,3 , and 4 , subordinate sows spent more time sitting than dominants $(P<0.05$; Figure $1(\mathrm{a}))$, and had more frequent bouts of sitting behavior but only during period $3(P<0.001$; Figure $1(\mathrm{~b}))$. While the duration of sham-chew behavior ( 6.6 vs. 3.4 mins/4-h) was higher $(P<0.05)$ among dominant sows during time-period 2 (which included feeding) than subordinates, but subordinates had more $(P<0.05)$ frequent bouts of drinking $(11.9$ vs. 2.3 no) during time-period 3 than did dominants.

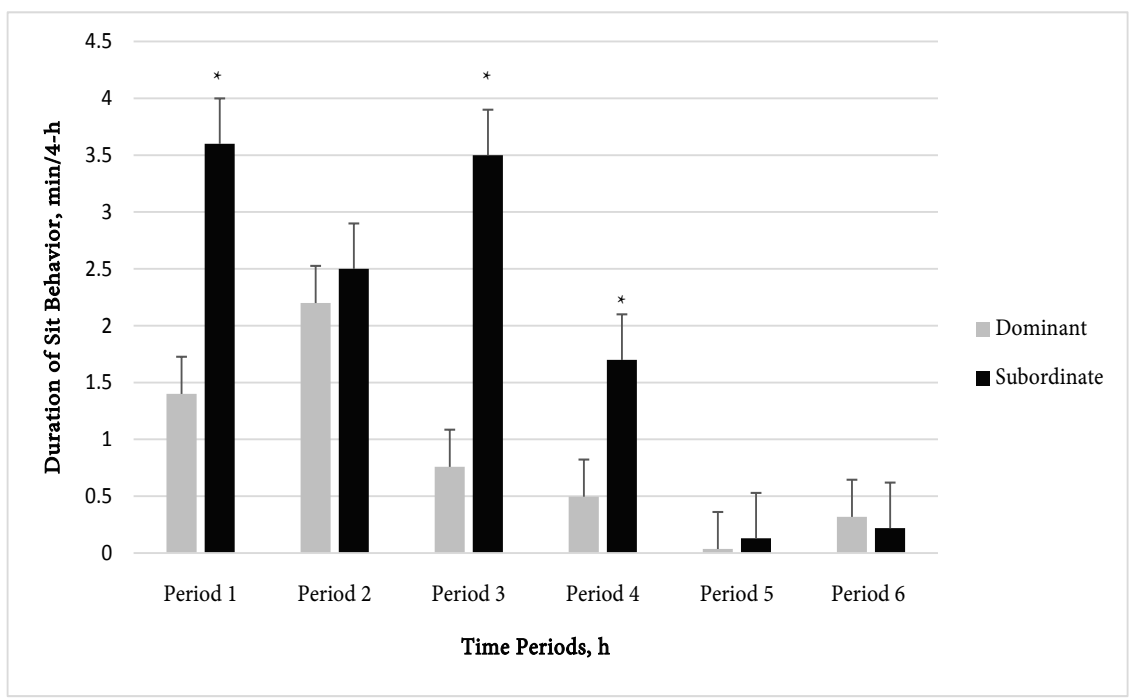

(a)

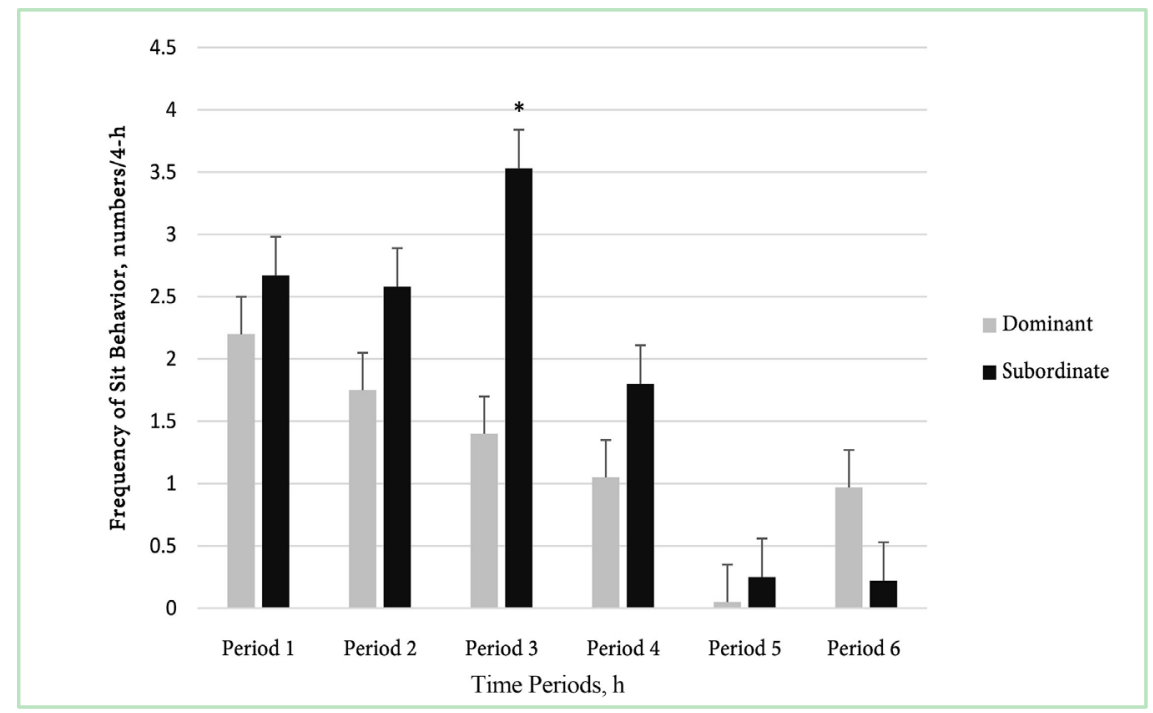

(b)

Figure 1. Effect of social rank by time-period on duration (a) and frequency (b) of sit behavior for dominant and subordinate sows kept in a free access stall-pen housing environment during gestation. ${ }^{\star}$ denotes $(P<0.05)$ difference of social rank within day of gestation. 


\subsection{Interactive Effect of Social Rank by Day or Time-Period on Space Utilization}

An interactive effect of social rank by gestational day (Figure 2) and time-period (Figure 3) occurred for the percentage of time sows used either the stall or pen space throughout gestation. Overall dominant sows spent a higher percentage of time in the open-pen area than did subordinates, with the percentage of time increasing from d 30 to 66 but remaining elevated throughout $\mathrm{d} 102(P<0.05$; Figure 2). Overall, dominant sows spent more time in the pen-area during time-periods 1 through 6 than did subordinates except for time-period 4 (1500 - 1900 h; Figure 3).

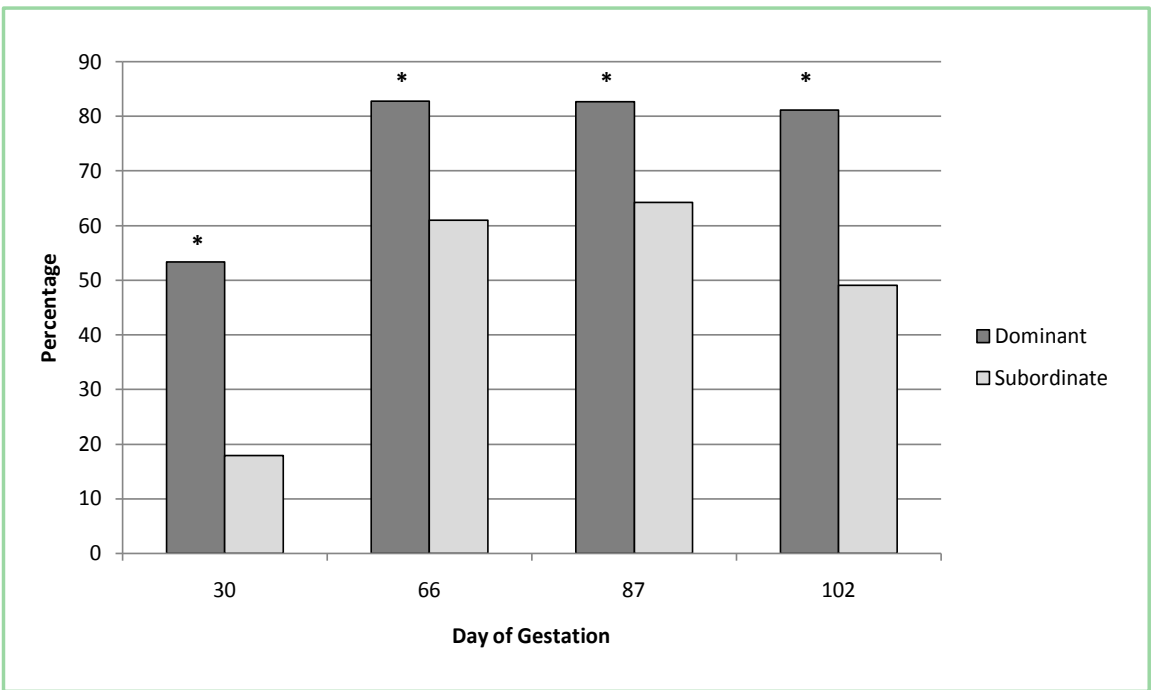

Figure 2. Effect of social rank by gestational day on percentage of time sows spent in the group-pen area of the free-access stall-pen housing environment at various days of gestation. ${ }^{*}$ denotes differences between social rank within day of gestation at $P<0.05$.

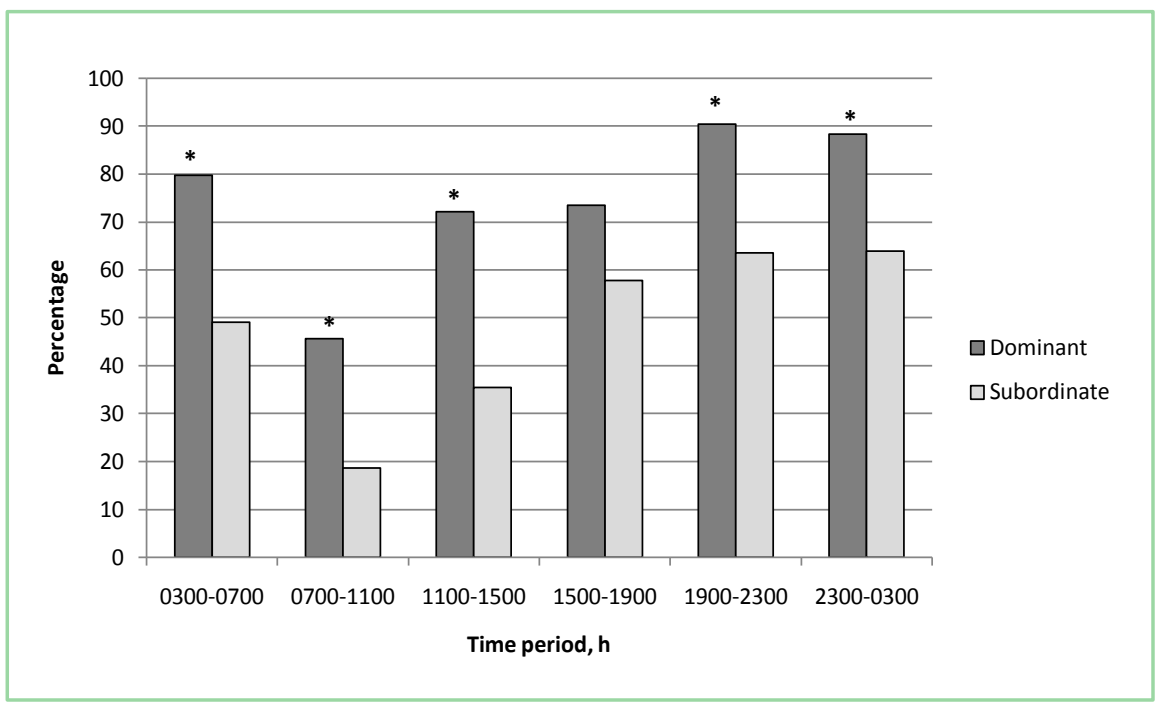

Figure 3. Effect of social rank by time-period on percentage of time sows spent in the group-pen area of the free access stall-pen housing environment throughout a $24-\mathrm{h}$ period. * denotes differences between social rank within time-period at $P<0.05$. 


\subsection{Social Rank Effects on Immune, Behavior, and Space Utilization}

Social rank did not affect cortisol or immune traits $(P>0.10$; Table 3$)$; however, there was a main effect of social rank on sow behavior (Table 4). Duration and frequencies of sit bouts were higher for subordinates than dominant sows $(P<$ 0.05; Table 4). Subordinate sows had more frequent bouts of drinking than dominants, but dominants spent more time displaying ONF behavior than did subordinate sows ( $P \leq 0.05$; Table 4$)$. In general, dominant sows spent a higher percentage of time in the group-pen area than subordinates $(P<0.001$; Figure 4$)$.

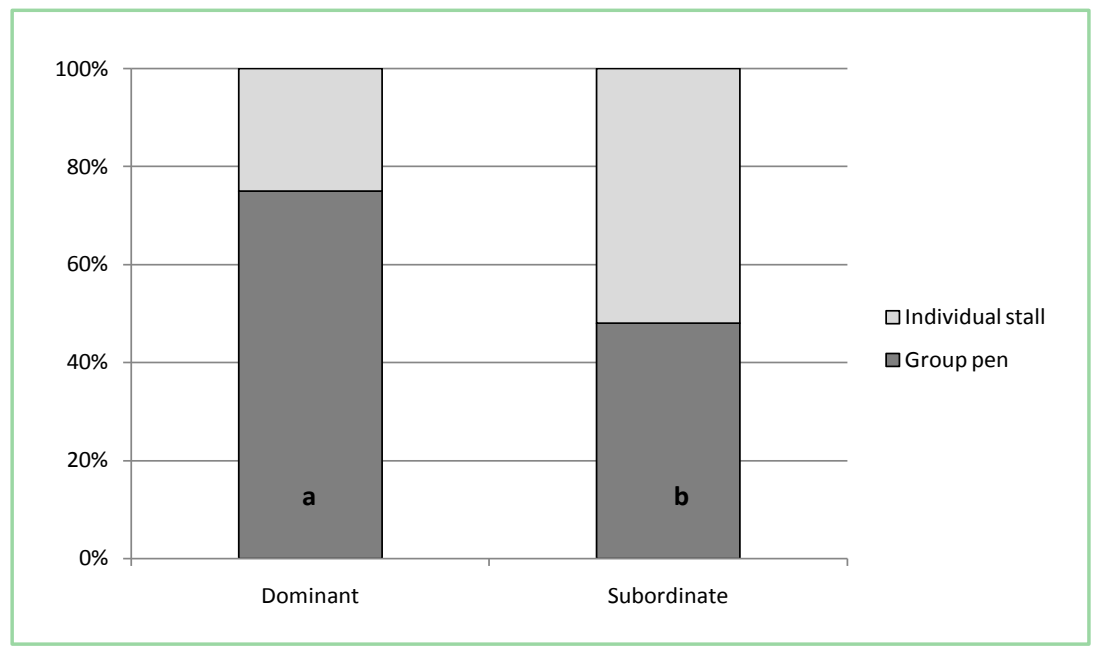

Figure 4. Main effect of social rank on percentage of time sows spent utilizing either group-pen area or individual stall space in a free-access stall-pen housing system. Means differ at $(P<0.001)$.

Table 3. Main effect of social rank on various immune traits and cortisol for sows kept in a free access stall-pen housing environment during gestation.

\begin{tabular}{lccc}
\hline & \multicolumn{2}{c}{ Social Rank } \\
\hline Immune trait & Dominant & Subordinate & $P$-value \\
\hline Total WBC, $10^{7} / 10 \mathrm{~mL}$ & $2.31 \pm 0.09$ & $2.30 \pm 0.09$ & 0.903 \\
Neutrophils, $10^{7} / \mathrm{mL}$ & $5.17 \pm 0.31$ & $5.17 \pm 0.31$ & 0.704 \\
Lymphocytes, $10^{7} / \mathrm{mL}$ & $2.86 \pm 0.14$ & $2.88 \pm 0.14$ & 0.905 \\
Neutrophils, \% & $39.3 \pm 1.6$ & $38.7 \pm 1.6$ & 0.794 \\
Lymphocytes, \% & $53.1 \pm 1.6$ & $53.3 \pm 1.6$ & 0.912 \\
Monocytes, \% & $3.24 \pm 0.3$ & $3.85 \pm 0.3$ & 0.183 \\
Eosinophils, \% & $4.42 \pm 0.4$ & $4.42 \pm 0.4$ & 0.997 \\
Neutrophil-to-lymphocyte ratio & $1.02 \pm 0.13$ & $0.82 \pm 0.13$ & 0.289 \\
LPS-induced proliferation index & $1.06 \pm 0.06$ & $1.12 \pm 0.06$ & 0.442 \\
ConA-induced proliferation index & $1.45 \pm 0.15$ & $1.23 \pm 0.14$ & 0.297 \\
NK cytotoxicity, \% & $46.7 \pm 8.0$ & $43.1 \pm 7.9$ & 0.746 \\
Chemotaxis, IL-8 & $52.1 \pm 8.5$ & $60.0 \pm 9.1$ & 0.529 \\
Chemotaxis, C5a & $54.6 \pm 9.3$ & $54.7 \pm 8.8$ & 0.994 \\
Plasma cortisol, ng/mL & $32.8 \pm 2.2$ & $34.9 \pm 2.2$ & 0.516 \\
\hline
\end{tabular}


Table 4. Main effect of social status on frequency and duration of postural, maintenance, and stereotypic behavior for sows kept in a free access stall-pen housing environment.

\begin{tabular}{|c|c|c|c|}
\hline \multicolumn{4}{|c|}{ Social Rank } \\
\hline Behavior & Dominant & Subordinate & $P$-value \\
\hline \multicolumn{4}{|l|}{ Lay } \\
\hline Frequency, no. & $15.3 \pm 1.4$ & $14.3 \pm 1.4$ & 0.60 \\
\hline Duration, min & $86.0 \pm 5.0$ & $84.1 \pm 4.9$ & 0.79 \\
\hline \multicolumn{4}{|l|}{ Sit } \\
\hline Frequency, no. & $7.3 \pm 1.1$ & $10.8 \pm 1.1$ & 0.03 \\
\hline Duration, min & $0.86 \pm 0.18$ & $1.9 \pm 0.17$ & $<0.001$ \\
\hline \multicolumn{4}{|l|}{ Stand } \\
\hline Frequency, no & $12.6 \pm 1.4$ & $13.6 \pm 1.3$ & 0.60 \\
\hline Duration, min & $21.0 \pm 2.6$ & $21.2 \pm 2.5$ & 0.95 \\
\hline \multicolumn{4}{|l|}{ Eat } \\
\hline Frequency, no & $4.7 \pm 1.5$ & $4.8 \pm 1.4$ & 0.987 \\
\hline Duration, min & $2.3 \pm 0.5$ & $2.1 \pm 0.5$ & 0.756 \\
\hline \multicolumn{4}{|l|}{ Drink } \\
\hline Frequency, no & $13.1 \pm 5.1$ & $27.5 \pm 5.0$ & 0.05 \\
\hline Duration, min & $0.35 \pm 0.04$ & $0.31 \pm 0.04$ & 0.60 \\
\hline \multicolumn{4}{|l|}{$\mathrm{ONF}^{*}$} \\
\hline Frequency, no. & $33.3 \pm 4.2$ & $35.8 \pm 4.1$ & 0.67 \\
\hline Duration, min & $9.3 \pm 1.6$ & $5.1 \pm 1.5$ & 0.05 \\
\hline \multicolumn{4}{|l|}{ Sham-chew } \\
\hline Frequency, no. & $18.7 \pm 3.0$ & $18.5 \pm 3.0$ & 0.96 \\
\hline Duration, min & $3.0 \pm 0.33$ & $2.9 \pm 0.33$ & 0.85 \\
\hline
\end{tabular}

${ }^{*} \mathrm{ONF}=$ Oral-Nasal-Facial.

\section{Discussion}

Animal welfare reflects the successful adaptation of the individual, not the population [14]. The degree of the welfare of individuals within a group varies greatly [15], and is partly associated with social status [16], which is one of the most critical and overlooked factors that contribute to welfare variation. These data imply that sow social rank is a critical factor that influences the appropriate physiological and behavioral response in her attempt to cope with social and environmental stressors when kept in a free access stall-pen housing environment. Moreover, the social relationship between sows also influenced how and when they utilized the stall and group-pen area. According to Salak-Johnson and McGlone [17], the social status of an individual often plays a more significant role in the stress responsiveness within the group than the stress itself. For example, $24 \mathrm{~h}$ after moving sows to the free access stall-pen environment, regardless of social rank, an acute stress response was evoked. However, the magnitude of change for several immune traits was affected by social rank when compared to the baseline sample 
of the sow before mixing, resulting in differential effects on the immune measures. More specifically, the subordinates, had a more stimulated innate immune response as indicated by enhanced neutrophil numbers and function (chemotaxis) despite a reduction in total WBC counts 24 -h after moving groups of sows into the free-access stall-pen environment. At the same time, dominant sows had an enhanced T-cell response (ConA), but a reduced B-cell response (LPS) compared to their baseline measure. However, it should be noted that among subordinates, both total lymphocytes and ConA-induced lymphocyte proliferation increased but no effect on LPS-induced lymphocyte proliferation compared to baseline levels. Previously, it was reported that mitogen-induced lymphocyte proliferation increased in dominant pigs after mixing, whereas it decreased in subordinate pigs [18]. Regardless, 24-h post mixing both dominant and subordinate sows had an acute stress response to the new environment and social grouping; however, it seems that the subordinates were better able to cope by retreating to the individual stalls to avoid conflict.

DeDecker [19] reported that the aggressive encounters in the group-pen area among these sows subsided and was rarely observed beyond 2 weeks post-mixing (gestational $d 45$ ). The subordinates spent the majority of their time within the walk-in/lock-in stall instead of the group-pen area, ultimately isolating themselves from the dominant sows. Especially during the day and early evening hours (time-periods 1 through 4), implying that the subordinates were most likely avoiding conflict from higher-ranking sows and that being locked in the individual stalls protected them. Often, higher-ranking sows control valuable resources, which dictates lower-ranking sow behavior [20], but in the FAS environment, during feeding sows are protected since the stalls have a locking mechanism which enables them to consume their entire feed allotment. Often, low-ranking sows become fearful of further conflicts, especially in their attempt to obtain feed, resulting in less weight gain and poorer body condition, compared to higher-ranking sows due to inadequate feed intake [21] [22]. Nevertheless, this was not the case here because there were no differences in cortisol, immune status, or lesion and body condition scores between dominants and subordinates throughout gestation [19], most likely due to being able to avoid conflict, especially during feeding. Therefore, the difference in space utilization may be indicative of varying perceptions of social stress among subordinates.

Dominance hierarchy is primarily maintained by avoidance behavior of the subordinate sow rather than the overt aggression of the dominant sow [23], perhaps subordinates spending more time in stalls of the FAS environment, especially during the times when the dominant sows were active was beneficial to both. Dominants spent $70 \%$ to $80 \%$ of their time in the group-pen area while subordinates spent $40 \%$ to $50 \%$, mostly during late-night hours in which all sows were inactive. These results are in agreement with others who reported that dominant sows spend more time utilizing the group-pen area than did lower-ranking sows [24]. Still, others report that larger-bodied sows spend more time in the group-pen area than smaller sows mainly due to space restriction in stalls, insuf- 
ficient space in the group-pen area, or pen design [15] [19] [25]. However, we speculate that the dominant sows may influence the activities of the other sows based on their location within the free access stall-pen housing environment. For example, subordinate sows were more active during the afternoon and early evening hours and occupied the pen area with the other sows when the dominant sows were least active. These findings are similar to those reported [20] in which subordinates would access resources while dominant sows were inactive. Other behaviors such as drinking and sitting were performed more often throughout the day among subordinates compared to dominants, especially drinking behavior. Subordinates performed more drinking behavior after the feeding period while dominant sows performed more sham-chew behavior during the actual feeding time, which was similar to previous research in that sows expressed more oral activity before, during, and after feeding as well [26] [27]. Moreover, during the 1900 to $0300 \mathrm{~h}$, all sows utilized the group-pen area, including subordinates, implying that during the late-night hours, the pen is used as a communal resting area. Even though the sample size is relatively small, DeDecker [19] reported that the percentage of time sows spend in the group-pen area is positively correlated with lay behavior but negatively correlated with stand behavior, further supporting this theory. These results imply that social rank does significantly influence the behaviors of animals in a group pen setting. That dominant and subordinate sows may change their times of activity based on con-specifics location and activity.

\section{Conclusion}

These preliminary results demonstrate that the degree of welfare for individuals even in a free access stall-pen housing environment is partly associated with their social rank within the group, thus resulting in differential physiological and behavioral responses evoked as they attempt to adapt. Moreover, subordinate sows may change their activity budget and location preference within the free access stall-pen housing environment based on con-specifics location and activity, especially higher-ranking sows. Overall, these findings indicate the social rank of individuals within small groups housed in a free-access stall-pen environment may benefit from having the opportunity to avoid aggressive encounters during feeding and time-periods in which higher-ranking animals most active, especially subordinates.

\section{Acknowledgements}

The National Pork Board supported this research. The authors gratefully acknowledge the farm staff at the University of Illinois Imported Swine Facility for assistance with animal care, and Chore-Time and Laake companies for supplying the free access stall system.

\section{Conflicts of Interest}

The authors declare no conflicts of interest regarding the publication of this paper. 


\section{References}

[1] Bench, C.J., Rioja-Lang, F.C., Hayne, S.M. and Gonyou, H.W. (2013) Group Gestation Housing with Individual Feeding-I: How Feeding Regime, Resource Allocation, and Genetic Factors Affect Sow Welfare. Livestock Production Science, 152, 208-217. https://doi.org/10.1016/j.livsci.2012.12.021

[2] O'Connell, N.E., Beattie, V.E. and Moss, B.W. (2003) Influence of Social Status on the Welfare of Sows in Static and Dynamic Groups. Animal Welfare, 12, 239-249.

[3] Ison, S.H., D’Eath, R.B., Robson, S.K., Baxter, E.M., Ormandy, E., Douglas, A.J., Russell, J.A., Lawrence, A.B. and Jarvis, S. (2010) "Subordination Style" in Pigs? The Response of Pregnant Sows to Mixing Stress Affects Their Offspring's Behavior and Stress Reactivity. Applied Animal Beahviour Science, 124, 16-27.

https://doi.org/10.1016/j.applanim.2010.02.001

[4] Wang, L.H. and Li, Y.Z. (2016) Effect of Continuous Access to Feeding Stalls during Mixing on Behavior, Welfare, and Performance of Group-Housed Gestating Sows in Different Social Ranks. Canadian Journal of Animal Science, 96, 386-396. https://doi.org/10.1139/cjas-2015-0054

[5] National Research Council (1998) Nutrient Requirements of Swine. 10th Revised Edition, the National Academies Press, Washington, DC.

https://doi.org/10.17226/6016

[6] Tanida, H., Motooka, A., Seki, K., Tanak, T. and Yoshimoto, T. (1993) The Feeding Behavior of Group-Housed Pigs Using a Computerized Individual Feeding System. Animal Science Technology (Japan), 64, 455-461. https://doi.org/10.2508/chikusan.64.455

[7] Andersen, I.L., Boe, K.E. and Kristiansen, A.L. (1999) The Influence of Different Feeding Arrangements and Food Type on Competition at Feeding in Pregnant Sows. Applied Animal Behaviour Science, 65, 91-104. https://doi.org/10.1016/S0168-1591(99)00058-1

[8] Sutherland, M.A., Rodriquez-Zas, S.L., Ellis, M. and Salak-Johnson, J.L. (2005) Breed and Age Affect Baseline Immune Traits, Cortisol, and Performance in Growing Pigs. Journal of Animal Science, 83, 2087-2095. https://doi.org/10.2527/2005.8392087x

[9] Salak, J.L., McGlone, J.J. and Lyte, M. (1993) Effects of in Vitro Adrenocorticotrophic Hormone, Cortisol, and Human Recombinant Interleukin-2 on Porcine Neutrophil Migration and Luminal-Dependent Chemiluminescence. Veterinary Immunology and Immunopathology, 39, 327-337. https://doi.org/10.1016/0165-2427(93)90065-C

[10] Jolie, R., Backstrom, L., Olson, L. and Chase, C. (1999) Respiratory and System Health Parameters in Pigs Raised in a Conventional Farm or in Isolation. Swine Health and Production, 7, 269-275.

[11] Niekamp, S.R., Sutherland, M.A., Dahl, G.E. and Salak-Johnson, J.L. (2007) Immune Responses of Piglets to Weaning Stress: Impacts of Photoperiod. Journal of Animal Science, 85, 93-100. https://doi.org/10.2527/jas.2006-153

[12] SAS 9.3. Statistical Analysis Software. SAS Institute Inc., Cary.

[13] Hanson, A.R., DeDecker, A.E., Salak-Johnson, J.L. and Walker, P.M. (2011) A Comparison of Using Pen versus Individual Sow as the Experimental Unit When Evaluating Data from Sow Housing Studies. Journal of Animal Science (E-Supplement), 2,5 .

[14] Ohl, F. and van der Staay, F.J. (2012) Animal Welfare: At the Interface between Science and Society. Veterinary Journal, 192, 13-19.

https://doi.org/10.1016/j.tvjl.2011.05.019 
[15] Rioja-Lang, F.C., Hayne, S.M. and Gonyou, H.W. (2013) The Effect of Pen Design on Free Space Utilization of Sows Group Housed in Gestation Pens Equipped with Free Access Stalls. Applied Animal Behaviour Science, 149, 93-98. https://doi.org/10.1016/j.applanim.2013.07.002

[16] Li, Y.Z., Wang, L.H. and Johnston, L.J. (2017) Effects of Social Rank on Welfare and Performance of Gestating Sows Housed in Two Group Sizes. Journal Swine Health Production, 25, 290-298.

[17] Salak-Johnson, J.L. and McGlone, J.J. (2007) Making Sense of Apparently Conflicting Data: Stress and Immunity in Swine and Cattle. Journal of Animal Science, 85, E81-E88. https://doi.org/10.2527/jas.2006-538

[18] Tuchscherer, M., Puppe, B., Tuchscherer, A. and Kanitz, E. (1998) Effects of Social Status after Mixing on Immune, Metabolic, and Endocrine Responses in Pigs. Physiology and Behavior, 64, 353-360. https://doi.org/10.1016/S0031-9384(98)00084-5

[19] DeDecker, A.E. (2011) Effect of Alternative Individual, and Group Housing Systems, and Management Factors in Group Pens on the Well-Being of Gestating Sows. PhD Dissertation, the University of Illinois at Urbana-Champaign, Urbana.

[20] Brouns, F. and Edwards, S.A. (1994) Social Rank and Feeding Behaviour of Group-Housed Sows Fed Competitively or Ad Libitum. Applied Animal Behaviour Sciences, 39, 225-235. https://doi.org/10.1016/0168-1591(94)90158-9

[21] Pacheco, E. and Salak-Johnson, J.L. (2016) Social Status Affect Welfare Metrics of Group-Housed Gestating Sows. Journal of Veterinary Research Animal Husbandry, 1, 103-108.

[22] Kranendonk, G., Van der Mheen, H., Fillerup, M. and Hopser, H. (2007) Social Rank of Pregnant Sows Affects Their Body Weight Gain and Behavior and Performance of the Offspring. Journal of Animal Science, 85, 420-429. https://doi.org/10.2527/jas.2006-074

[23] Jensen, P. and Wood-Gush, D.G.M. (1984) Social Interactions in a Group of Free-Ranging Sows. Applied Animal Beahviour Science, 12, 327-337. https://doi.org/10.1016/0168-1591(84)90125-4

[24] Gonyou, H., Lang, F., Hayne, S.M. and Heron, V. (2011) Free Space Utilization of Sows in Free Access Stall. Pig Progress, Vol. 27, nr 2.

[25] Mack, L.A., Lay Jr., D.C., Eicher, S.D., Johnson, A.K., Richert, B.T. and Pajor, E.A. (2014) Group Space Allowance Has Little Effect on Sow Health, Productivity, or Welfare in a Free-Access Stall System. Journal of Animal Science, 92, 2554-2567. https://doi.org/10.2527/jas.2013-7352

[26] Blackshaw, J.K. and McVeigh, J.F. (1986) The Behaviour of Tethered Sows When Given the Opportunity to Exercise. Proceedings of Australian Society of Animal Production, 16, 147-150.

[27] Vieulle-Thomas, C., Le Pape, G. and Signoret, J.P. (1995) Stereotypies in Pregnant Sows: Indications of Influence of Housing System on the Patterns Expressed by the Animals. Applied Animal Behaviour Science, 44, 19-27.

https://doi.org/10.1016/0168-1591(95)00574-C 